\title{
Towards a Constructional Account of Indefinite Uses of Proper Names in Modern Greek ${ }^{1}$
}

\author{
Sophia Marmaridou \\ University of Athens \\ smarmari@enl.uoa.gr
}

\section{Abstract}

This paper addresses the issue of Modern Greek proper names, within the framework of Construction Grammar. More specifically, proper noun headed nominal constructions will be the focus of attention. Unlike earlier accounts that view common and proper nouns as grammatically, semantically and functionally distinct from each other, the present investigation provides evidence for constructional properties these categories have in common. It will be shown that in Modern Greek a proper noun as head of a nominal construction unifies with determiners and adjectives in the same way that common nouns do. Moreover, like common nouns, proper noun heads activate semantic frames associated with particular categories of entities (e.g. persons, cities, cars, etc.). Additionally, proper noun frames are contextually rich. More specifically, the use of a proper noun activates a frame which is so rich in information specificity that in this frame the name identifies a unique referent. This referent can provide metonymic access to various aspects of the frame when the proper noun is the head of a nominal construction. Significantly, metonymic uses of proper nouns in indefinite constructions, varying in degree of conventionality, are often associated with a subjective viewpoint and rate high in expressivity. Apparently, the findings of this study argue for a holistic, constructional approach to proper names and a frame-based analysis of their use. The present corpus-based analysis adopts a Construction Grammar

1 I am greatly indebted to the Dept. of English Language and Literature of the Univ. of Thessaloniki and the organizing committee of ISTAL20 for inviting me to give a plenary talk at the conference. This paper has benefited from several participants' comments, questions, and suggestions and especially from a long discussion with Joseph Emonds. All shortcomings are, of course, my own.

\section{(cc) BY-NC-ND}


framework and notation after Fried \& Östman (2004) to highlight inheritance relations and unification principles among the relevant constructions. Moreover, the investigation makes reference to mental space theory and conceptual blends as in Fauconnier (1997) and the concept of frame-metonymy as in Sweetser and Fauconnier (1996). Therefore, the present work argues for a usage-based perspective on language and a principled exploration of its cognitive, cultural, and constructional motivations.

\section{Introduction}

The present study aims to show that a Construction Grammar framework provides useful insights to the analysis of proper names, which has been an issue of much controversy in both philosophical and linguistic discussions for more than a century. It is further argued that, being a holistic, usage-based theoretical model, Construction Grammar is compatible with other cognitive, usage-based approaches to linguistic analysis, including mental space theory. Finally, the theoretical stance taken in this paper entails a methodological commitment to a corpus-based approach to the data and a consideration of all semantic, syntactic, pragmatic, and discoursal features of proper noun headed constructions. Following Huddleston (1988: 96), the distinction between proper nouns and proper names is maintained; a proper noun is a grammatical noun subclass, while a proper name results from naming practices and can be a proper noun, such as Thessaloniki or John, but need not be, as names like The United Nations indicate. As will become evident subsequently, the nominal constructions to be analysed in this paper are headed by proper nouns which constitute personal proper names in Modern Greek.

The debate about the origin, meaning and function of proper names dates at least as far back as the end of the $19^{\text {th }}$ and the beginning of the $20^{\text {th }}$ century within the framework of the philosophy of language (see, for example, Mill (1956[1843], Frege (1892), and Russell (1905), among others). More specifically, while Mill (1956[1843]) argued that proper names only have denotation, or reference, and do not connote (i.e. mean) anything at all, Frege (1892) claimed that apart form that which the name designates (i.e. denotation), there is also that which contains the way in which the denotation of a name is given. In this respect, like common nouns, proper names denote in virtue of the propositional content of the descriptions associated with them (e.g. Aristotle was a philosopher). Subsequent discussions by Russell (1905), Strawson (1950), and Searle (1969) essentially adopt Frege's views, while Kripke (1972), Putnam (1975), and Donnellan (1975) not only consider proper names as rigid designators devoid of any kind of meaning, but also extend this account to the category of natural kinds, such as cats, cows, lions, etc. 
Their basic argument is that the extension of natural kinds is not determined by concepts that represent basic characteristics of these kinds, but instead are like proper names whose extension is determined by ostension and/or something like a causal chain that associates a term with its referent or the object to which it applies.

More recently, this issue has been addressed from a variety of linguistic viewpoints, as in Zwicky (1974), Hawkins (1978), Allerton (1987), Carroll (1985), Marmaridou (1984), (1989), and (1991), Langacker (1991), Van Langendonck (1999), Lehrer (1992), Vandelanotte \& Willemse (2002), and Dancygier (2009) and (2011), among others. The interest in proper names mainly follows from two issues. The first relates to the obvious fact that even though proper names are primarily used to uniquely identify referents in the universe of discourse, they are also used to indicate that this is not in fact the case, as in the examples below:

(1) John Carpenter arrived in a limo.

(2) I knew a John Carpenter at school.

The co-occurrence of the name with the indefinite article in (2) suggests that there is possibly more than one referent known by that name. In fact, several uses of proper names relax the uniqueness requirement, as shown in almost all recent work cited above. The second issue concerns the grammatical form of proper names. For example, even though proper names in English prototypically occur in the bare form of nominals (i.e. without determiners or other type of modification), they are frequently part of constructions that are typical of common nouns in the language, as example (2) indicates above. Moreover, grammatical similarity in proper name uses does not guarantee similarity in meaning, as (3) and (4) below suggest:

(3) A furious Thatcher entered the Cabinet meeting earlier this afternoon.

(4) A beautiful Standhal was hanging on their living-room wall.

Clearly, there is only one Thatcher in the current universe of discourse and the name uniquely identifies this referent on a particular occasion. Similarly, there is only one painting hanging on the wall, but the name is used metonymically to refer to it as one of several paintings. In this sense, the indefinite article cannot be dissociated from the meaning of singularity it also encodes. Moreover, the adjective modifying the proper name in (3) indicates a temporary quality of the referent, while in (4) the work of art is attributed a permanent quality by the modifying adjective.

The variability in the meaning and use of proper names is also attested in the Modern Greek language, in which proper names are typically preceded by 
the definite article o/i/to ('the') in their referential uses, but also frequently cooccur with the indefinite determiner enas/mia/ena ('a/an'), for the three genders respectively. Their bare form occurs only in non-referential uses, as is the case with common nouns in this language. The following examples illustrate these points:

(5) 0 mitsotakis ektimise tis psifotirikes ikanotites the mitsotakis appreciate-3rd.sg.pst the vote-soliciting capabilities tu neu politiku the-gen young-gen politician-gen.

'Mitsotakis appreciated the vote-soliciting abilities of the young politician.' $(\text { HNC 449816) })^{2}$

(6) enas papavlasopulos se pire. Pjos ine; A papavlasopulos you call-3rd.sg.pst Who be-3sg.pr?

'A Papavlasopoulos called you. Who is he?' (oral example attested by the author)

(7) ala tus perimene enas diaforetikos, apetitikos karamanlis but them wait-for 3sg.pst a different, demanding Karamanlis 'But a different, demanding Karamanlis was waiting for them.' (HNC 658997)

(8) periexi ke arketa plasta erya anamesa sta opia enas maleas, contain-3rd.sg.pr and several fake works among in-the which a aleas

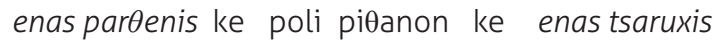
a parfenis and very probably and a tsaruxis 'It also contains several fake paintings, among them a Maleas, a Parthenis and, most likely, a Tsarouxis.' (GkWaC 7695)

(9) an ke iudas $\delta$ en ejina pote

if and Judas not become-1st.sg.pst never

'even though I never became a Judas' (GkWaC 1279)

The subject nominal in (5) illustrates the prototypical, referential use of proper names: reference is made to a specific individual, known to both the author of the article it appears in and the reader. In (6) the referent identified by

2 The Modern Greek corpora consulted include the HNC (Hellenic National Corpus, 47m. words) and the GkWaC (Greek Web as Corpus, 150m. words) operated by Sketchengine. 
the indefinite nominal is unknown to the speaker and, possibly, to the addressee. The only thing known about this person is his name, i.e. Papavlasopoulos, which morphologically identifies the referent as a male human being. The indefinite nominal in (7) has a different function from that of (6). Reference is made to a specific entity known to both speaker and addressee, but the indefinite determiner and the modifying adjectives present the referent on a specific occasion, i.e. when, unlike his typical self, he was more demanding. Apparently, the nominal signals a temporary characterization of the referent similar to that in (3). The indefinite noun phrases in (8) illustrate the well-entrenched metonymy whereby the name of a painter stands for one of his or her works to which reference is made. Finally, (9) exemplifies a non-referential use of a culturally salient name, aiming to evoke the sense of a traitor.

In view of the above, the aim of this paper is to address the issue of the use of Modern Greek personal names, and surnames in particular, within the framework of Construction Grammar. More specifically, proper noun headed nominal constructions will be the focus of attention. Unlike earlier accounts that view common and proper nouns as grammatically, semantically, and functionally distinct from each other, the present investigation provides evidence for constructional properties these categories have in common. It will be shown that a proper noun as head of a nominal construction unifies with determiners and adjectives in the same way that common nouns do. Moreover, like common nouns, proper nouns activate semantic frames associated with particular categories of entities, e.g. human beings, animals, locations, etc. Additionally, proper noun frames are contextually rich. More specifically, the use of a proper noun activates a frame which is so rich in information specificity that, in this frame, the name identifies a unique referent. This referent can provide metonymic access to various aspects of the frame when the proper noun is the head of an indefinite nominal construction, as in examples (7) and (8). Significantly, metonymic uses of proper nouns in indefinite nominal constructions, varying in degree of conventionality, are often associated with a subjective viewpoint and rate high in expressivity. Therefore, the findings of this study argue for a constructional analysis of proper names and a framebased analysis of their use.

At a methodological level, the present corpus-based analysis adopts a Construction Grammar framework and notation after Fried \& Östman (2004) to highlight inheritance relations and unification principles among the relevant constructions. Moreover, the investigation makes reference to mental space theory as in Fauconnier (1997) and the concept of frame-metonymy as presented in Sweetser and Fauconnier (1996). Overall, the present work draws on a usagebased perspective on language and a principled exploration of its cognitive, cultural, and constructional motivations. To the extent that generalizations pertaining to the English language and used in linguistic theorizing by several 
scholars have been brought to bear on Modern Greek data, this study may be said to also adopt a cross-linguistic perspective.

In the next section some principles of Construction Grammar will be set out with a view to highlighting those aspects of the theory that are particularly relevant for the analysis of the data. In the third section the challenges posed by the use of proper names will be set off against the background of more recent research that will inform the present study. In the next section referential and nonreferential uses of proper names in Modern Greek will be shown to depend on the occurrence or non-occurrence of determiners respectively, following a general pattern of the grammar of nominal constructions in this language. In the fifth section indefinite nominals headed by proper nouns will be examined and the relevant constructions will be highlighted and fully described. In the last section, and on the basis of the analysis proposed, it will be argued that Construction Grammar, as a usage based approach to the study of linguistic units, is well suited to an account of proper names, whose use not only combines aspects of form and meaning, but also crucially involves pragmatic and discoursal attribute values.

\section{The Construction Grammar Framework}

Before proceeding any further it is perhaps important to set out some basic principles of Construction Grammar that bear on the proposed analysis, and the notation to be used in it.

\subsection{Historical Background}

Construction Grammar as a distinct model of linguistic analysis has been around for at least twenty years now. It started with work by Fillmore and Kay in Berkeley around the eighties and initially led to a number of important publications in Language in the eighties and nineties. It subsequently extended in the direction of information structure by Lambrecht (1994), argument structure by Goldberg (1995), and formal semantics by Kay (1997). The integration of Construction Grammar and Fillmore's Frame Semantics - the latter developed much earlier - led to the well-known application of FrameNet, as reported in Johnson et al. (2001). The long established view that language change is pragmatically motivated and affects form and meaning at the same time (see Hopper and Traugott (1993); Traugott and Dasher (2002)), made Construction Grammar particularly suitable for investigating instances of language change and was therefore enhanced in works such as Leino \& Östman (2005), Hoffmann \& Trousdale (2011) and Gisborne (2011). It soon became clear that this model could be extended to also account for discourse regularities. Interest in that area is rapidly increasing, as reflected 
in Fried \& Östman (2003), Nikiforidou (2010) and (2011), and Antonopoulou \& Nikiforidou (2011), among others. Expectedly, grammatical constructions shed new light on the analysis of interaction as work by Fried \& Östman (2005), Fox \& Thomson (2007), Fried (2009), and Terkourafi (2010) reveals. Finally, given the theoretical commitment of Construction Grammar to account for linguistic units as constructs combining form and function, this framework was soon adopted by researchers such as Waara (2004), Broccias (2008), and Valenzuela Manzanares \& Rojo López (2008) in the area of second language teaching and learning.

\subsection{General Principles}

Construction Grammar is a theory of language that, like many others, aims to represent the relationship between structure, meaning, and use. However, unlike other theories of language, it sees function and form as inseparable from each other, thereby introducing the notion of grammatical construction as the basic unit of analysis and representation, and as comprising information on all levels of linguistic analysis, from the level of phoneme to the level of text. In this framework language is seen as the inventory of its constructions; knowing a language is knowing its constructions. Moreover Construction Grammar has empirical goals in that, while aiming at maximally relevant generalizations and aspiring to capture cross-linguistic generalizations, it views the existence of language universals as an empirical matter, rather than an article of faith.

More specifically Construction Grammar entertains the hypothesis that speakers rely on relatively complex meaning-form patterns - grammatical constructions - for building linguistic expressions. Constructions are organized into networks of overlapping patterns related through shared properties. Therefore, linguistic expressions reflect the effects of interaction between constructions and linguistic material (e.g. words) that occur in them.

The primary motivation for Construction Grammar is the insight that the juxtaposition of two or more forms seldom results in a simple concatenation of the meanings those forms might have in isolation (Fried \& Östman 2004: 12). This motivation justifies a number of methodological principles. First of all, a uniform representation of all grammatical knowledge in the speaker's mind is sought. Second, both words and clauses have constructional properties and are represented as constructions. Third, linguistic units, as particular associations between form and meaning, are represented by multiple inheritance taxonomic networks (Croft \& Cruse 2004: 262-265). Therefore, no priority (theoretical or methodological) is given in this model to particular language forms, e.g., active, declarative, transitive clauses, and no a priori decision is required about what should count as "basic" or the "core" in language. In this context, an account of what are usually considered "peripheral" parts of language is both 
methodologically desirable and fully justifiable in that such parts constitute the majority of structures used in everyday discourse, while they are not explicitly taught. It follows that the relation between "productive rules" and "idioms" is seen as a cline from relatively productive to relatively frozen. Consequently, linguistic units such as "Thank you" or "See you" are as central to English as "John loves Mary", or "The book, which Susan read, is on the table".

Support for the view that an adequate description of linguistic structure needs to make reference to complex constructions rather than to a generative capacity of a rule system comes from cognitive correlates of language processing. It has been argued that we process language in larger blocks, in gestalts (Chafe, 1994; Pawley, 1987; Pawley \& Syder, 1983). Memory and language storage function in terms of larger formulas rather than in terms of words or phrases. We talk in terms of prosodic units rather than in terms of one word or one linguistic phrase at a time. As Bolinger $(1951 ; 1976)$ has long argued, we make use of "prefabs" in language, including the prosodic patterning of language. Levels of an intonation contour are not particularly salient for speakers; rather, they serve as cues in the context of intonation contours as wholes. The above is also consistent with what we know about cognition and language acquisition. Recent advances in research on child language show that our cognitive processes manipulate linguistic structures of varying sizes and complexity (Peters, 1983; Praine \& Brooks, 1995; Tomasello 1992, 2000; Goldberg 2006).

\subsection{The Grammatical Construction}

In Construction Grammar grammatical constructions are symbolic signs that represent the basic building blocks of linguistic analysis (e.g. morpheme, word, phrase, text, etc.). All grammatical constructions can be placed on a lexicon-syntax continuum. A construction is an abstract, conventional, representational entity providing a blueprint for licensing well-formed linguistic expressions (Fried $\&$ Östman 2004: 18). The actually occurring linguistic expressions such as phrases, sentences, etc. are constructs. It follows that we use constructs to communicate - not constructions. Constructions can vary in degree of complexity. They may represent simple configurations, such as [Det $+\mathrm{N}$ ], which any phrase-structure grammar could account for. However, the Construction Grammar framework is particularly suited to represent much larger and complicated patterns, containing syntactic, semantic, pragmatic, etc. layers of information. For example, it should be able to account for instances of proper name use, such as those represented in (7) and (8) above, crucially making reference to the semantics of indefinite nominals and encyclopaedic information activated by the proper noun used. It is therefore a multi-dimensional framework. In this model it is important to realize that linguistic expressions typically "reflect the effect of interaction between 
constructional patterns and the words that fit in them: words, whether heads or dependents, contribute specific semantic properties to any larger construction they occur in, but a construction may also modify some of those properties, as well as add features of its own" (Fried \& Östman 2004: 22).

Given the complexity of linguistic patterns that Construction Grammar addresses, it becomes important to formalize relationships holding between linguistic elements in the attempt to explicate and understand them. Therefore appropriate notation is used as a convenient way of providing a construction with its phonological, morphological, syntactic, semantic, pragmatic, discourse, and prosodic characteristics. Three major notation devices are used in Construction Grammar. The first concerns boxes-within-boxes diagrams representing constituent structure and capturing dominance relations and the linear order of constituents. External characteristics of a construction as a whole are represented in outer boxes. Internal constituents of a construction are represented in inner boxes. The distinction between external and internal domains is crucial, given that a construction as a whole is typically not a sum of its parts. The possible discrepancies between the external and internal properties may have to do either with a mismatch in form, or with a non-compositional meaning of the construction. ${ }^{3}$ The second device concerns feature structures providing grammatical information in terms of attributes and values. For example, in the nominal construction in (5) above, the morphological attributes [gender], [case], and [number] take as their values the features [masculine], [nominative], and [singular], respectively. The third device is co-indexation for keeping track of unification relations. For example, in the same example, for the determiner to unify with the proper noun, they have to be co-indexed for the same gender, case, and number. An important aspect of Construction Grammar is that when two or more grammatical patterns show partial overlap, such that one pattern is a more constrained version of another, it is assumed that inheritance relations are at work. In this sense, inheritance relations between constructions keep track of properties along which these constructions resemble each other. For example, if the proper noun construction inherits the common noun construction, then it contains all the specifications that hold for the common noun construction, in addition to features idiosyncratic to the proper noun construction. The Construction Grammar notation and its theoretical underpinnings will become clearer in the proposed analysis of proper names.

3 There is no general agreement on the requirement for formalization among linguists subscribing to Construction Grammar. For example, boxes-within-boxes diagrams were introduced by Fillmore in the early stages of the particular framework and later adopted by Fried and Östman, among others, but not by Goldberg (see references at the end of this paper). 


\section{Philosophical and Linguistic Perspectives on Proper Names}

This section aims to present a number of issues that have arisen in philosophical and linguistic approaches to proper names, with a view to highlighting some aspects of their use that justify further investigation. In linguistic treatments, in particular, the scope varies between morpho-syntactic accounts and semantico-pragmatic ones. It is perhaps not a coincidence that revived interest in this category has been noted in the last decade, when advances in Cognitive Linguistics and Construction Grammar have enabled a holistic approach to the investigation of linguistic units, whereby all information resides on one and the same level of representation and actual constructs are licensed, rather than generated, by particular abstract constructions.

A perennial issue concerning the analysis of proper names is whether they have meaning or not, and if so, how this meaning relates to their referential function. Within the philosophical tradition of truth-conditional semantics, where the distinction between sense and reference is the cornerstone of semantic analysis, the 'meaning' of proper names is a matter of controversy. Frege (1892), Russell (1905), and Searle (1969), among others, claim that the meaning of a proper name consists of a number of propositions that truly describe its referent. This descriptivist view is juxtaposed to the communication chain view, in which the reference of a term is not given by a description, but rather by a chain of communication that starts with the initial dubbing of a name for an individual and continues with the successive use of this term by people in order to refer back to this individual (see e.g., Mill (1956[1843]); Kripke (1972)). It is not the aim of this paper to go into the arguments that have developed over this issue in any detail. What is of interest, though, is that, despite their differences, what both philosophical approaches seem to have in common is the assumption that proper names identify unique referents in the world, or universe of discourse. It is this assumption that has been successfully handed down to linguistic approaches to the analysis of proper names, and has motivated the interest in the grammatical status and function of members of this category as distinct from common nouns.

In a discussion of issues of reference and definiteness, Marmaridou (1984) focuses on the Modern Greek definite article o/i/to and argues that this determiner is primarily a marker of reference. One of the arguments offered is its obligatory co-occurrence with proper names, which are definite par excellence in their referential function, and its absence from non-referential uses. Within a pragmatic, relevance-theoretic framework, Marmaridou (1989) is an attempt to approach the analysis of proper names from the point of view of communication and cognition. It is specifically argued that a proper name 
"itself activates the formation by the hearer of an appropriate context in which the name ... can only identify one referent ... the name is not interpreted against a pre-existing context, but rather itself selects one among several contexts in which it is appropriately paired with a specific referent" (ibid: 363). In this analysis, what determines the selection of a particular context is the search for optimal relevance in communication, in the sense of Sperber $\&$ Wilson (1986). Apparently, though, the selection of the appropriate context is also constrained by linguistic and cultural convention. For example, Allerton (1987) distinguishes seven broad categories that get names and Lehrer (1992) provides evidence for a system of culturally specified naming choices. More specifically, it is demonstrated that native speakers have intuitions about how to name members of a particular lexical field and that naming, though creative, is highly constrained. (ibid: 140). Similarly, Marmaridou (1991), adopting a socio-cultural perspective, examines the use of names in literary works and identifies meaning-creating and meaning-created proper names (e.g. Godot in Becket's famous play and Sophia in Fielding's Tom Jones as a wise and virtuous girl, respectively), thereby arguing for a cultural constraint on the use of proper names.

A grammatical perspective on proper names has usefully brought forward the distinction between proper nouns and proper names. Following Huddleston (1988), Lehrer (1992: 124-125) notes that a proper noun is a grammatical noun subclass, while a proper name is the institutionalized name of some entity. A proper name may have the form of a proper noun, i.e. London, Jack, etc., but it need not do so. Thus, the Open University is a proper name, but the older university is not. It is also observed, though, that the difference between common and proper nouns is anything but clear-cut, given the variability of name forms to include common word classes and the fact that proper nouns are often used as non-referring expressions. By contrast, Van Langendonck (1999) argues for a clear distinction between proper and common nouns on the basis of the non-descriptive and ad hoc assignment of the former. In answer to the apparent fact that linguistic and cultural convention attribute minimal semantic (e.g. categorical) content to proper names, he claims that, semantically, proper names do not have asserted lexical meaning, but do display presuppositional meaning, including categorical (basic-level), associative (introduced via the name-bearer or via the name form), and grammatical meanings (ibid: 95). More importantly from the point of view of the present paper, Van Langendonck (ibid: 101-102) introduces a further distinction between a dictionary lemma and a word in a particular semantic-syntactic function. According to this view, a proprial lemma, i.e. a word that prototypically functions as a proper name (e.g. Mary, John, the Thames), is to be distinguished from its semantic-syntactic functions. This distinction motivates his analysis of the proper names in (10) and (11) 
as employed in their primary identifying function, whereas in (12) and (13) as having a secondary, describing function:

(10) John attended a meeting today.

(11) Napoleon was defeated at Waterloo.

(12) You are talking about a different John.

(13) He is becoming a second Napoleon.

Clearly, the proper names in (12) and (13) are acting as common nouns, i.e. they have the semantic-syntactic function typically assigned to common nouns. Van Langendonck claims that this secondary function is linked to the primary one by operations like metonymy, as in (12), and metaphor, as in (13). This analysis is not without its problems. The proper names in both (12) and (13) are heads of an indefinite nominal construction, but they are functionally distinct in that the one in (12) performs a referential function, while the one in (13) performs a predicate function. It is not clear whether the author is actually claiming that referential functions of proper noun headed indefinite nominals are metonymic, while nonreferential ones metaphorical. Moreover, this analysis does not explain why in (12) one is speaking of at least two different persons called John, while in (14) below reference is made to one and the same individual called Putin, while both proper noun headed indefinite nominals perform the same referential function in the respective examples.

(14) It appears that we re now dealing with a different Putin..

(WebNews, reported in Dancygier (2011: 223)

Apparently, there is more to the analysis of proper names than semanticsyntactic considerations of function, which needs to be specified at a more global level so that various parameters of use, including semantic, pragmatic, and cultural, can be taken into account. It will be proposed that such parameters can be specified at constructional level.

Adopting the view that proper names are rigid designators, which is not without its problems as already noted, Vandelanotte and Willemse (2002) follow Van Langendonck's distinction between proprial lemmas as dictionary entries and proper names as a semantic-syntactic class, with a view to classifying instances of the latter in terms of modification, including articles, numerals, demonstratives, and adjectives. Essentially, the authors identify grammatical constructions, in which the name either denotes a referent other than the one it typically associates with, thereby functioning as a common noun with a categorizing or type-specifying meaning, as in (15) and (16) below, or the name refers uniquely, as in (17) and (18), but some additional information is provided concerning the referent. 
(15) That Picasso is not on exhibition at the moment.

(16) This country will be fine until the next Margaret Thatcher comes along.

(17) I can't live in a sad and misty Paris.

(18) It was in a sad and misty Paris that the general was carried to his grave.

Notably, the definite article and demonstratives modify the name only when the proprial lemma functions as a common noun and therefore extends its 'lexical' meaning metonymically or metaphorically, as in (15) and (16). The indefinite article is said to modify the proprial lemma both when functioning as a common noun, as in (17), and when functioning to identify a unique referent, as in (18). However, the boundary between the two functions in the latter two examples is not clear. According to the authors, in both of these examples the modified name indicates a temporary property of the same referent, but (17) involves a restrictively modified proprial lemma used as a common noun (e.g. a sad and misty Paris as opposed to a bright and shining one), whereas (18) involves a non-restrictively modified proprial lemma used as a proper name (e.g. Paris, which, as you know, is sad and misty). However, this distinction is not borne out by the data, possibly because the context in which (17) and (18) occur is not provided. If there is such a distinction, as the authors assume, and context is important in identifying it, then it is possible to argue for the contextual, or discoursal, motivation of the respective functions. In the absence of any further contextual parameters, the identity of the referent is the same, but in (17) the referent is apparently modified for properties that characterize it time and again, whereas in (18) the modification seems to apply to a particular span of time, i.e. a day. In this understanding, the name in both examples identifies a unique referent whose description by the modifying adjectives applies on different occasions. It should also be noted that the constructional pattern instantiated by both examples seems to reflect the speaker's attitude towards the referent identified. This is not unrelated to the type of adjectives used to modify the specific referent and the use of the indefinite article. As it turns out, differences in the understanding of a modified proper name may relate to various attributes of the grammatical construction of which it is a part, such as contextual, discoursal, and attitudinal, expressing speaker involvement.

It transpires from the above discussion that the distinction between proprial lemmas and proper names, like that between proper nouns and proper names, is a useful one in so far as it contributes to the realization that the analysis of proper names cannot be dissociated from the nominal constructions in which they occur. Moreover, this distinction brings forward the need to specify constructional attributes of proper names at various levels of linguistic analysis, including semantic, syntactic and pragmatic, thereby justifying a Construction Grammar framework for this task. In what follows, proper names in Modern Greek will be examined in more detail. 


\section{Referential and Non-Referential Uses of Proper Names in Modern Greek}

The examination of proper names is related to the issue of the Modern Greek nominal construction in an obvious sense. Unlike English, proper nouns in Greek typically unify with the definite article $o / i /$ to in their referential function, thereby following the general pattern of noun headed constructions. Proper nouns unifying with indefinite determiners, such as enas/kapjios, are also systematically attested as referring expressions, cancelling the uniqueness presupposition, as it were. Therefore, the unification of proper nouns with determiners follows from a general pattern of Modern Greek nominals.

It has long been argued (Marmaridou 1984) that in Modern Greek, determiners characterize the referential function of noun phrases, whereas non-referential predicate functions are typically characterized by absence of determiners. Grammatical descriptions of this language also reflect this point. In Construction Grammar terms, the unification of a noun head with a determiner specifies an instance of a type, $T_{i j}$. When a noun head does not unify with a determiner, the nominal specifies a type $T$ (following Langacker 1991: 55). A special class of verbs, commonly termed copulative and/or auxiliaries, including ime (be), jinome (become), exo (have), and kano (do), typically select for complements specifying a type, i.e. they unify directly with noun heads, unless the noun head is modified by a relative clause (Marmaridou 1984; Mackridge 1985; Joseph and Philippaki 1987; Holton et al. 1997). ${ }^{4}$ In this latter case, the noun head unifies with a determiner. The two types of predicate nominals are exemplified in (19) and (20) below:

(19) ine

pseftis

be-3rd.sg/pl.pr liar-sg.masc

'He is a liar.' (HNC 605965)

(20) o iroas ine enas fititis pu vioni mia katastasi stasimotitas the hero be-3rd.sg.pr a student who experience-3rd.sg.pra situation stagnation-gen 'The hero is a student who is experiencing a state of stagnation.' (GkWaC 68282)

In (19), the predicate noun head is a phrasal constituent and directly unifies with the copula. Semantically, this predicate nominal specifies the type of entity

4 Manolessou \& Horrocks (2007: 228) note that predicative nominals lack the article throughout the history of Greek. 
the subject of the sentence is, i.e. pseftis (a liar). By contrast, in (20), the noun head, modified by a relative clause, unifies with a determiner to form a phrasal constituent. In this case the predicate nominal specifies an instance of the type fititis (student), i.e. one that is experiencing a particular state. For the purposes of the present discussion it is assumed that the two types of predicate nominals instantiate two different constructions, i.e. the Type Nominal Construction and the Instance Nominal Construction, respectively.

Proper nouns follow this pattern, as examples (5)-(9) indicate above, the first four illustrating the referential function and the last one the predicative function. Non-referential functions are also attested extra-sententially as vocatives and across verbs of naming, as the following examples indicate: ${ }^{5}$

(21) Katina, ise monasiki.

Katina, be-2nd.sg.pr unique

'Katina, you are unique!' (HNC 2421300)

(22) lejete pavlidis leandros

called-3rd.sg.pr.pass Pavlidis Leandros

'He is called Pavlidis Leandros.' (GkWaC 689)

Focusing on definiteness as a complement taking category within the framework of formal syntax, Anderson (2004: 441) observes that proper names as arguments are complements of the definite article in Modern Greek, whereas in vocatives and across naming contexts, as in (21) and (22) above, definiteness is not assumed; rather identity is assigned and therefore the definite article is absent. He further concurs that, when used as arguments, or referential terms, they constitute the primary means of establishing the identity of arguments, i.e. of ensuring that both speaker and addressee know the identity of a particular argument (ibid: 439). There are at least two problems with this analysis. The first concerns the relation between definiteness and reference. If definiteness is defined as establishing identity, as in (5) above, it is not clear how it differs from assigning identity, as in (21) and (22), both of which, according to Anderson, do not express definiteness. Apparently, in both (5) and (21) speaker and addressee know the identity of the referent bearing the name. In (22) the identity of the referent is pragmatically available to speaker and addressee, possibly from previous discourse, but now it is simply paired with a name. If definiteness applies to referents known to both speaker and addressee, then

5 Even though vocatives are not used to refer to entities whose existence is presupposed, they do confer addressee status to such entities, thereby establishing them as referents and enabling future reference to them. This point will not be further addressed in the present discussion. 
it characterizes the use of names in both (5) and (21) and no distinction can be drawn between these examples on the basis of this property. The difference between (5) on the one hand and (21) and (22) on the other seems to lie in the referential use of the name in (5) and the non-referential uses in (21) and (22), rather than in definiteness itself. Secondly, Anderson (2004) offers no account of the co-occurrence of proper names with indefinite determiners. Working within a formal syntactic model of analysis, in which definiteness, but not indefiniteness, is a complement taking phrasal head, Anderson (ibid.) overlooks the fact that not only as complements of the definite article, but also when preceded by indefinite determiners do proper names have a referential function, as example (6) illustrates above. As also argued elsewhere for Modern Greek (see Marmaridou 2012) and following Langacker (1991), in such cases, as in all instances of indefinite reference, the indefinite nominal indicates that the speaker, and possibly the addressee, does not have mental contact with the referent the name identifies. ${ }^{6}$

In what follows, an attempt will be made to provide an account of some indefinite uses of personal proper names in Modern Greek following the Construction Grammar framework. It will be argued that the uses illustrated in (6)-(8) above inherit the Indefinite Nominal Construction in the language, but (7), (8), and (23) below are further constrained semantically and pragmatically. More specifically, uses like those illustrated in (7) and (8) make reference to frame metonymy (see Sweetser and Fauconnier (1996)) as part of the semantics of the construction, while the semantics and pragmatics of the use illustrated in (23) depend on a conceptual blend of relevant mental spaces (after Fauconnier (1997):

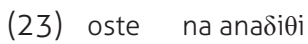

kapjia stiymi enas Mozart i enas Picasso so that to emerge-3rd.sg.prs.pass some moment a Mozart or a Picasso 'so that a Mozart or a Picasso emerge at some point'

On the basis of the proposed analysis it will be argued that, even though proper nouns differ from common nouns in that the understanding of the former depends on much richer frames than that of the latter, both categories function as heads in the same nominal constructions in the language, which are further elaborated into more specific constructions accounting for their various uses.

6 For the view that the definite article in Modern Greek is a semantically neutral marker of reference and compatible with pragmatically established definiteness, whereas indefinite determiners are semantically marked for indefiniteness see Marmaridou (1984), and (2012) for a modified view concerning the indefinite article only. For a brief overview of definiteness in formal syntax, see Marmaridou (2011). For the view that enas/mia/ena is a marker of indefiniteness rather than an article in Modern Greek, see Chila-Markopoulou (2000). 


\section{Indefinite Proper Noun Constructions in Modern Greek}

For the purposes of the analysis, it will be assumed that the Indefinite Nominal Construction in Modern Greek, formalized in Figure $\mathbf{1}$ below, inherits the Instance Nominal Construction, as specified in section 4 above. As already mentioned, according to Construction Grammar notation, inner boxes represent the constructional specifications of the constituent parts, whereas the outer box represents the whole construction, which need not be a sum of the constituent parts, but may be characterized by additional features specific to the construction as a whole.

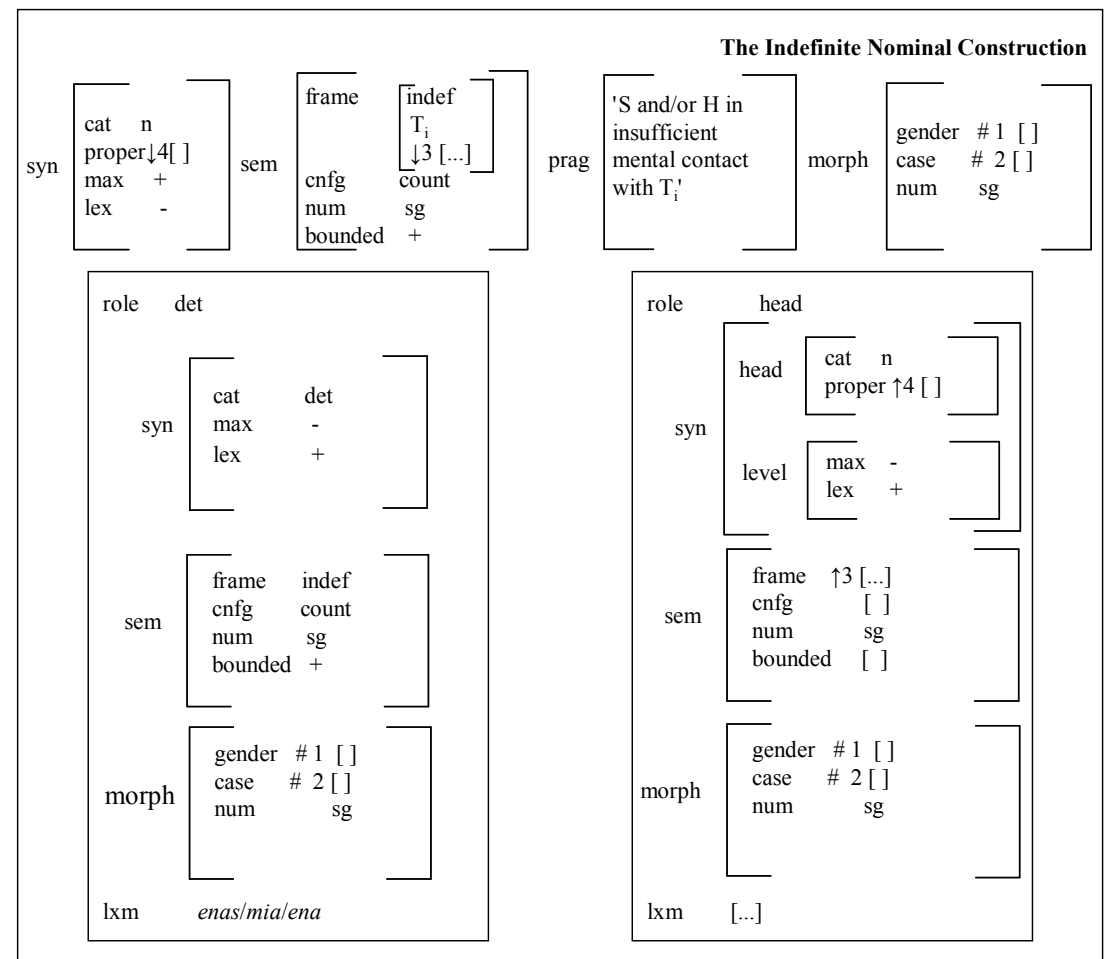

Figure 1. The indefinite nominal construction in Modern Greek

One of the claims made in Figure 1 at the syntactic level is that both common and proper nouns may be nominal heads, hence the unspecified value of the syntactic head for the attribute [proper]. Moreover, each of the constituent constructions, i.e. the nominal head and the determiner, has lexical, but not 
phrasal status, hence they are both characterized as [lex +] [max -], i.e. they are lexical but not phrasal constituents.

At the semantic level, the semantic frame of the nominal head may take a number of values depending on the lexical choice of the head. As already mentioned, a common noun has meaning in terms of the semantic frame it activates and denotes a category, all members of which are characterized by the same frame.7 A proper noun has meaning in terms of a category-specific semantic frame (e.g. human being, city, animal, etc.), which is encyclopaedically enriched to the extent that in that frame only one member of the category can be identified. This seems to be the basis of the uniqueness requirement for the use of proper names. For example, the use of the name Mozart activates a frame of classical music in which a human being is uniquely identified as a famous composer. Apparently, proper nouns are associated with much richer frames than common nouns, in that they activate both category membership, or, in Langacker's (1991) terms, type-specification, and rich encyclopaedic information, e.g. classical music, composers, etc., which need not be activated by respective lexical frames, e.g. the words 'music', 'composer', etc. As Dancygier (2011: 211) observes, if this information is not available to the addressee, he or she will not be able to pair the name with a referent, even though they will recognize the particular form as a proper name. Unlike Dancygier (ibid.), though, I further claim that a proper noun head of a construction activates an expectation of uniqueness, even when frame information is not available. In other words, it is part of cultural knowledge that, if a word form is recognized as a proper noun, it is expected that it should identify a unique referent in some frame or other. The use of a proper noun, referential or otherwise, may vary depending on the construction of which it is part, but the frame is activated in all of them. For example, in Modern Greek a frame is activated by a proper noun in both (either definite or indefinite) referential and non-referential uses, as shown in all examples above.

A further claim made in Figure 1 is that, even though the nominal head itself may be semantically unspecified for number, count status, and mass/unit attribute values, when it unifies with an indefinite determiner, it selects for the attribute values of the determiner. In the examples above, the indefinite determiner enas/

7 Lexical analysis in terms of semantic frames originates in Fillmore (for an overview see Fillmore (1985)), who claimed that our knowledge of any linguistic form is available to us in connection with some personally meaningful setting or situation. These settings or situations comprise scenes which are associated with certain linguistic frames, so that scenes and frames activate each other in the language user's memory and are hence mutually retrievable. It follows that the process of communication involves the activation within speakers and across speakers of linguistic frames and cognitive scenes. The implication of this position is that in lexical analysis a word cannot be separated from its context if an adequate account of its meaning is to be given. 
mialena selects for singularity, countability, and boundedness values, which also characterize the proper noun heads in the respective utterances. To the extent that these attribute values have morphological correlates, the latter are also specified for both the nominal head and the determiner in the respective constituent constructions.

It follows from all the above and the outer box in Figure 1 that the Indefinite Nominal Construction is syntactically a phrasal, [max +], non-lexical, [lex -], constituent, headed by a common or proper noun, which semantically identifies an instance of a type $\left[T_{i}\right]$, a singular, countable and bounded entity, with which, at a pragmatic level, the speaker and/or the hearer are in insufficient mental contact (following Langacker 1991). ${ }^{8}$

On the basis of this analysis, I would like to claim that the use of the proper name in (6) above directly instantiates the Indefinite Nominal Construction in that it constitutes a phrasal syntactic category, which semantically activates a frame in which an instance of the type 'human being' is identified as bearing the culturally available family name Papavlasopoulos, morphologically marked as a male, singular, bounded entity. The question following the name expression ('who is he?') in example (6) confirms that the speaker, and possibly the addressee, has no mental contact with this person.

As already mentioned, the use of the name in (7) does not identify a person who is unknown to the speaker or the addressee. Therefore, indefiniteness cannot apply to the referent. I would like to suggest that the semantics of the indefinite construction is further characterized by frame metonymy, as discussed in Sweetser \& Fauconnier (1996) in relation to examples such as The ham sandwich wants his check. It has been argued that the use of the ham sandwich for the customer who had a ham sandwich is not simply a case of part-for-whole metonymy, whereby the ham sandwich is a part for what the whole customer activity involves, but rather both the meal and the customer are parts of a restaurant frame, including customers, meals, checks, tables, waiters, etc. The authors argue that, because this frame is available to speakers of the language, is it possible to metonymically use the meal for the customer, or even the table for the customer, as in Table 3 wants his check, for example.

The frame of politics activated by Karamanlis in example (7), in which the name identifies a unique referent, includes specific information about this referent, namely that this person is generally a mild, easy-going, almost indifferent politician. This view is probably established by reports of his behaviour on

8 Strictly speaking, the semantic attribute value $\left[T_{i}\right]$ is specified in the Instance Nominal Construction which, as already mentioned, is inherited by the whole Indefinite Nominal Construction. This feature is incorporated in Figure 1 for ease of reference. 
several occasions requiring political decisions, activities, collaborations, etc. What (7) implies is that Karamanlis' behaviour on a particular occasion was different from the typical one, so that now he appeared demanding. ${ }^{9}$ Apparently, the proper name does not only activate one among several contexts in which it is appropriately paired with a specific referent, as Marmaridou (1989:363) and Dancygier (2009: 166) have argued; rather, given that the frame in which Karamanlis is paired with a specific referent also includes the referent's views, behaviour, decisions, etc., the proper name metonymically stands for this referent's behaviour on a particular occasion. In short, the name activates a frame in which a referent is selected to provide access to his behaviour on a particular occasion. Note that this indefinite nominal construction is used to express the speaker's assessment of the situation described. According to the author's view, on a particular occasion Karamanlis behaved contrary to expectations. I would like to claim that this evaluation of the situation indicates a degree of subjectivity, i.e. speaker/author involvement as a pragmatic attribute value of this construction.

Example (8) can be similarly analysed. Each name activates a corresponding frame in which a specific referent is identified as a famous painter. The frame also includes associated information about the outcome of a painter's work, style, market price, originality, etc. In this frame, the name of the painter metonymically stands for each one of his/her works. The conventionality of this metonymy to refer to paintings is worth noting: one does not expect to find similar metonymic references to musicians' or poets' works (in fact, the corpora consulted confirm this view), even though such instances cannot be excluded. It is not inconceivable that one could say something like "exi ena aftendiko Skalkota sti siloji tu" ('s/he has an authentic Skalkotas in his/her collection') to refer to an original score by the famous Greek musician. Moreover note that the conventionality of the metonymy in (8) prompts for the understanding that reference is made to each famous painter's painting, even though it is clearly stated in the rest of the utterance that each of these paintings is a forgery.

The example in (23) differs from those in (6)-(8) in that, while each proper name activates a frame in which the name identifies a unique referent, Mozart and Picasso, each referent intended in (23) is other than the one typically associated with this name. The utterance, of which (23) is a part, constitutes an argument for the recognition of gifted children's talent and their guidance by specialists in a field, so that musicians like Mozart, or painters like Picasso, can

9 The meaning of siaforetikos (different) and alos (other) in collocations with prosopo (face) to refer to aspects of one's character and behaviour is also discussed in Marmaridou (2011). 
eventually emerge. Clearly, (23) is an evaluative statement making reference to artistic quality associated with Mozart in the domain of music and Picasso in that of painting. It could be argued that the name in these cases metonymically stands for artistic quality in the respective domains. In fact, this is the line taken by Barcelona (2004) in relation to predicate uses of paragon names, as in That young man is a real Shakespeare, i.e. a great playwright. However, in (23) the names do not simply stand for qualities. Rather the use of each name in this example makes reference to a specific, yet unknown and hence indefinite, child that is gifted by Mozart's or Picasso's talent. In this case, the frame evoked by each proper name is applied to another referent selectively, in the sense that not everything we know about Mozart or Picasso is mapped on each of the children (Dancygier 2011: 215), but only the culturally entrenched and contextually motivated feature of artistic excellence.

To explain this use, reference will be made to mental spaces and conceptual blends, after Fauconnier (1997). Both of these theoretical notions relate to meaning construction as resulting from high-level complex mental operations that apply within and across domains when we think, act, or communicate. The domains include background cognitive models (e.g. film-making, politics, art, music, etc.) as well as locally introduced mental spaces. Local spaces may be introduced by various linguistic expressions, including proper names, which set up elements in the discourse and can also associate such elements with properties like "having the name Mozart", "being an excellent music composer", etc. A connection of elements between two mental spaces, say $(R)$ and $\left(R^{\prime}\right)$, enables them to function as inputs to a third space that "blends" elements from the other two. Conceptual blending is a cognitive process operating on two input mental spaces to yield a third space, the blend. The blend inherits partial structure form the input spaces and, importantly, has emergent structure of its own (ibid: 149).

As already mentioned, the individuals to whom reference is made in (23), the gifted children, are not those typically identified by the respective names. Following Marmaridou (2012), I put forth the view that this is an instance of a conceptual blend, in the sense of Fauconnier (1997), motivating the semantics of the nominal construction and represented in Figure 2 below.

In one of the input spaces, (R), the two names, Mozart and Picasso, activate frames of classical music and modern art, respectively, in which two unique individuals are identified, the one associated with the property of being an excellent music composer and the other with that of being an excellent modern painter. In the second input space ( $\left.R^{\prime}\right)$ there is a set of indefinite, unspecified individuals. A connector links Mozart and Picasso in the first input space with indefinite, unspecified individuals in the second input space. In the blend there is a set of indefinite, unspecified individuals, one of whom is associated with the property of being an excellent music composer and the other with that of being an excellent painter. A pragmatic constraint of this construction is that the proper 


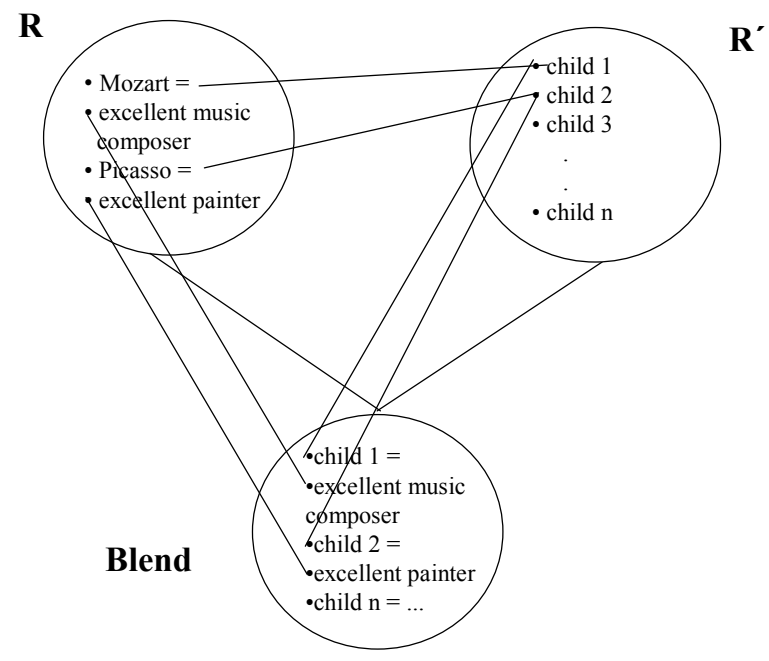

Figure 2. The blending semantics of the Indefinite Proper Name Construction instantiated in (23)

name(s) used must be culturally entrenched. Moreover, the utterance in (23) is used to argue for the benefits of early recognition of talent and in that sense the use of the names is associated with argumentative discourse. Importantly, each indefinite noun phrase expresses the speaker's subjective evaluation of an unspecified individual to whom reference is actually made. It follows that the noun phrases in (23) instantiate a construction, i.e. the Indefinite Proper Noun Construction, as formalized in Figure 3, which inherits the Indefinite Nominal Construction, and is further specified for "blending" semantics, the cultural pragmatics of the proper name used, argumentative discourse type, and speaker involvement in expressing a subjective view.

One of the claims formalized in Figure 3 is that it syntactically concerns the category of proper nouns. Moreover, in the proposed construction, the referent in space (R), i.e. the instance of the type named, $T_{i}$ (e.g. Mozart, Picasso), is culturally significant, as the unification index \#1 indicates in the semantic and pragmatic specifications of the construction. ${ }^{10}$ Furthermore, unification index \#2 shows that the property associated with the $T_{i}$ named (i.e. that of being an excellent composer or an excellent painter) is projected into the blend. More importantly for the understanding of the blend, the claim is also made that, by associating the indefinite $T_{i}$ in space $\left(R^{\prime}\right)$ with the particular property of excellence, the

10 Strictly speaking, the cultural significance of the name used follows from the encyclopaedically rich frame activated by the proper noun. 


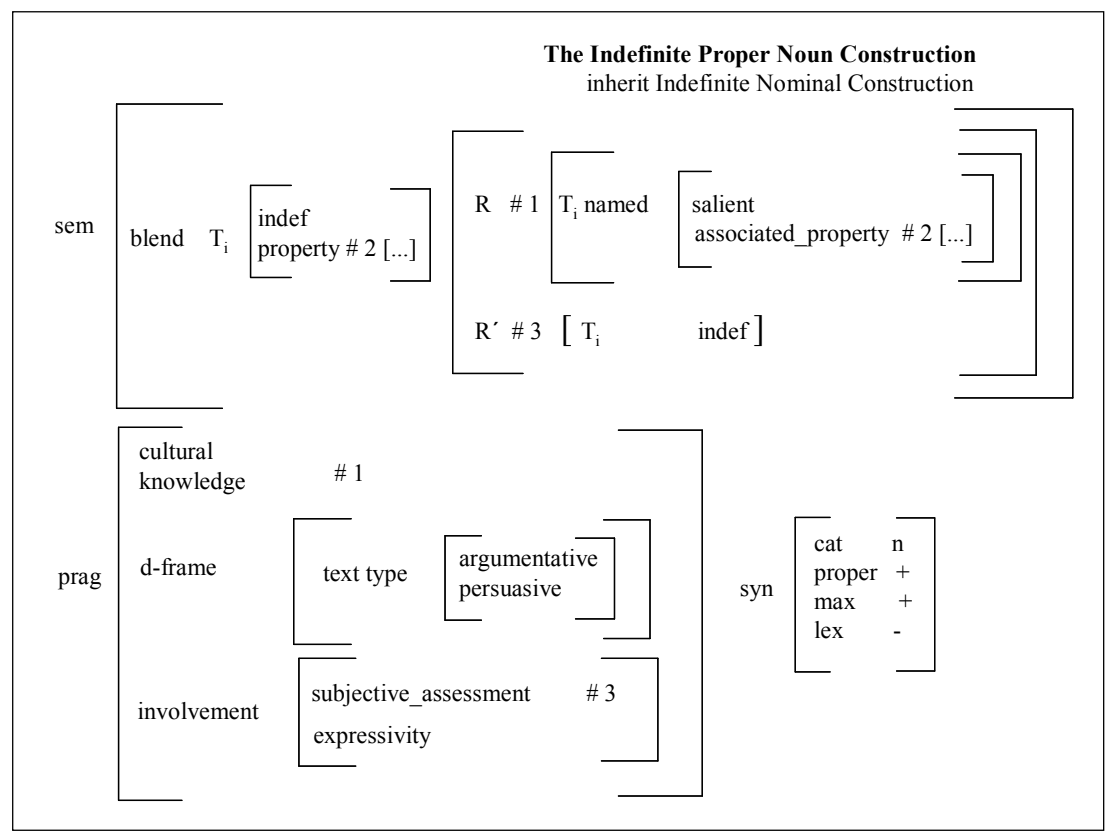

Figure 3. The indefinite proper noun construction in Modern Greek

speaker is making a subjective assessment of this indefinite $T_{i^{\prime}}$ i.e. the speaker expresses his/her judgement that these children will become famous artists (if appropriately discovered and trained), hence the unification index \#3. This judgement, instantiating speaker involvement, is used to argue for the need to discover such talented children early on in their lives; hence this construction is pragmatically motivated by the argumentative type of the discourse in which it occurs. Overall, Figure 3 shows that, apart from all the features that the proposed proper noun construction shares with the Indefinite Nominal Construction in the language, it is further characterized by additional semantic and pragmatic features comprising a conceptual blend operating on the basis of cultural information, as well as by discourse type and speaker involvement.

\section{Conclusions}

In this study an attempt has been made to analyse some indefinite uses of proper names in Modern Greek adopting a Construction Grammar framework and notation. On the basis of corpus examples it was argued that proper nouns, like 
common nouns in the language, unify with definite and indefinite determiners to establish referents in discourse. Their semantic difference lies in that, while a common noun activates a semantic frame that applies to all members of the type identified, a proper noun activates a frame in which a referent is uniquely identified on every occasion of use. Therefore, the uniqueness criterion of proper nouns is satisfied in the activation of such frames. For example, in (5) above, the proper noun activates the frame of politics in which a unique referent is identified. Note that, if more than one referent is identified by that name, for example when there are several members of the same family currently involved in the domain of politics, the actual referent intended must be pragmatically/ contextually specified, as is the case with definite reference in general.

As already mentioned, particular attention has been paid to indefinite uses of proper names, partly because their frequent occurrence challenges the long held view that proper names have definite reference by definition, but also because indefinite uses do not evoke the same understanding on each occasion. More specifically, the indefinite proper name sometimes identifies an unknown referent, as in (6) above, or the same referent on different occasions, as in (7), or a referent other than the one typically identified by the proper name, as in (8), or (23). Given such variability in the use of indefinite proper names, the present investigation proposes a unifying treatment of such uses within the framework of Construction Grammar. The analysis has shown that indefinite, proper noun headed constructions on the one hand inherit all those attribute values that characterize the Indefinite Nominal Construction in Modern Greek, as in (6) above, and, on the other, some of them are characterized by frame metonymy, as in (7) and (8), or are further specified semantically by conceptual blending and pragmatically by cultural knowledge, speaker involvement, and discourse type, as in (23). Moreover, it was shown that some indefinite proper noun headed constructions, such as the ones exemplified in (7) and (23), express subjective involvement and rate high in expressivity. Notably, these constructions, as special instances of the Indefinite Nominal Construction, license less conventional constructs in the language than those represented in (6) and (8).

This fact relates to the investigation of the Indefinite Nominal Construction in Modern Greek by Marmaridou (2012), who has argued that the indefinite determiner enas/mia/ena, semantically specified for indefiniteness and singularity, also contributes to speaker involvement and expressivity in a family of less conventional indefinite constructions in the language, including the Indefinite Proper Noun Construction exemplified in (23). On the basis of studies that view subjectivity, expressivity, and synchronic variability as prompts for language change (e.g. Hoffmann and Trousdale (2011)), it has also been argued that the specification of this indefinite determiner for these properties is conducive to its change into a semantically neutral article in Modern Greek. In view of the above, I would like to propose that the proper noun headed 
construction licensing constructs like (7) above also belongs to this family of indefinite constructions that contributes to the synchronic variability of enas/ mia/ena. Evidently, this claim further supports the view put forth in Marmaridou (2012) concerning the grammatical specification of the indefinite determiner in the language.

At least two implications follow from the proposed analysis. The first concerns the usefulness of a corpus-based approach to the data. Evidently, the identification of proper name uses has been facilitated by systematic corpus search, which has also revealed interesting frequencies of proper noun constructions. An informal count of seven names of politicians and artists indicates that indefinite uses constitute $17 \%$ of all their occurrences. A corpus-based approach has also enabled the identification of the contextual, discourse driven parameters regularly characterizing proper noun headed constructions, which would have otherwise gone unnoticed. The second implication relates to the appropriateness of Construction Grammar for an account of a linguistic category such as proper names. More specifically, the investigation of indefinite uses of proper names has necessitated the specification of a number or parameters at various levels of constructional analysis, which jointly characterize these uses. The Construction Grammar framework has been shown to provide the means for such integration since, by definition, a construction incorporates information at all levels. Moreover, given that it is a usage-based theoretical model, it can also incorporate insights from other usage-based approaches to linguistic analysis, such as frame semantics, extended to apply to frame metonymy, and mental space theory. It is certainly not a coincidence that both Construction Grammar and the theory of Conceptual Blends aim to account for the understanding of linguistic expressions whose meaning goes well beyond the meaning of the constituent parts, the latter represented as constituent constructions in the one model and input spaces in the other. The need to account for the systematicity of complex constructional patterns that do not simply constitute the sum of their parts can no longer be overlooked by linguistic theory. 


\section{References}

Allerton, D.J. 1987. The linguistic and sociolinguistic status of proper names. What are they, and who do they belong to? Journal of Pragmatics 11: 61-92.

Anderson, J.M. 2004. On the grammatical status of names. Language 80/3: 435474.

Antonopoulou, E. and K. Nikiforidou. 2011. Construction grammar and conventional discourse: A construction-based approach to discoursal incongruity. Journal of Pragmatics 43: 2594-2609.

Barcelona, A. 2004. Metonymy behind grammar: The motivation of the seemingly "irregular" grammatical behaviour of English paragon names. In G. Radden and K.-U. Panther (eds.), Studies in Linguistic Motivation. Berlin and New York: Mouton de Gruyter, 357-374.

Bolinger, D.L. 1951. Intonation: Levels versus configurations. Word 7/3(1): 199110.

Braine, M.D.S. and P.J. Brooks. 1995. Verb argument structure and the problem of avoiding an overgeneral grammar. In M. Tomasello and W.E. Merriman (eds.), Beyond names for things: Young children's acquisition of verbs. Hillsdale, N]: Lawrence Erlbaum, 353-376.

Broccias, C. 2008. Cognitive linguistic theories of grammar and grammar teaching. In S. De Knop \& T. De Rycker (eds.), Cognitive Approaches to Pedagogical Grammar. Berlin and New York: Mouton de Gruyter, 67-90.

Carroll, J.M. 1983. Toward a functional theory of names and naming. Linguistics 21: 341-371. 
Chafe, W. 1994. Discourse, consciousness, and time: The flow and displacement of conscious experience in speaking and writing. Chicago IL: University of Chicago Press.

Chila-Markopoulou, D. 2000. The indefinite article in Greek. A diachronic approach. Glossologia 11/12: 111-130.

Croft, W. and D.A. Cruse. 2004. Cognitive Linguistics. Cambridge: Cambridge University Press.

Dancygier, B. 2009. Genitives and proper names in constructional blends. In V. Evans and S. Pourcel (eds.), New Directions in Cognitive Linguistics. Amsterdam and Philadelphia: John Benjamins, 161-184.

Dancygier, B. 2011. Modification and constructional blends in the use of proper names. Constructions and Frames 3/2: 208-235.

Donnellan, K.S. 1975. Proper names and identifying descriptions. In D. Davidson and G. Harman (eds.), The Logic of Grammar. California: Dickenson Publishing Company Inc., 356-379.

Fauconnier, G. 1997. Mappings in Thought and Language. Cambridge: Cambridge University Press.

Fillmore, C. 1985. Frames and the semantics of understanding. Quaderni di Semantica 6: 222-254.

Fox, B.A. and S.A. Thomson. 2007. Relative clauses in English conversation: relativizers, frequency and the notion of construction. Studies in Linguistics 31/2: 293-326.

Frege, G. 1960[1892]. On sense and reference. In P.T. Geach and M. Black (eds.), Translation from the Philosophical Writings of Gottlob Frege. Oxford and New York: Oxford University Press, 40-65.

Fried, M. 2009. Construction Grammar as a tool for diachronic analysis. Constructions and Frames 1/2: 262-291.

Fried, M. and J.-O. Östman. 2003. The explicit and the implicit in the Suasion Frame. In E. Hajičová, A. Kotěšovoková, and J. Mírovský (eds.), Proceedings of CIL17. CD-ROM. Prague: Matfyzpress. 
Fried, M. and J.-O. Östman. 2004. Construction Grammar. A thumbnail sketch. In M. Fried and J.-O. Östman (eds.), Construction Grammar in a Cross-Language Perspective. Amsterdam and Philadelphia: John Benjamins, 11-86.

Fried, M. and J.-O. Östman. 2005. Construction Grammar and spoken language. The case of pragmatic particles. Journal of Pragmatics 37: 1752-1778.

Gisborne, N. 2011. Constructions, Word Grammar and grammaticalization. Cognitive Linguistics 22/1: 155-182.

Goldberg, A. 1995. Constructions. A Construction Grammar Approach to Argument Structure. Chicago: Chicago University Press.

Goldberg, A. 2006. Constructions at Work. The Nature of Generalization in Language. Oxford: Oxford University Press.

Hawkins, J.A. 1978. Definiteness and Indefiniteness. A Study in Reference and Grammaticality Prediction. London: Croom Helm.

Hoffmann, T. and G. Trousdale. 2011. Variation, change and constructions in English. Cognitive Linguistics 22/1: 1-23.

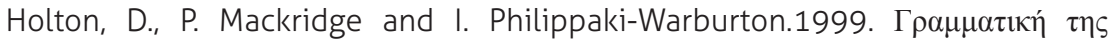

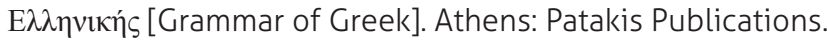

Hopper, P.J. and E.C. Traugott. 1993. Grammaticalization. Cambridge: Cambridge University Press.

Huddleston, R. 1988. English Grammar: An Outline. Cambridge: Cambridge University Press.

Johnson, C.R., C.J. Fillmore, E.J. Wood, J. Ruppenhofer, M. Urban, M. Petruck, and C.F. Baker. 2001. The FrameNet Project: Tools for Lexicon Building (Version 0.7, January 2001). Berkeley, CA: International Computer Science Institute.

Joseph, B. and I. Philippaki-Warburton. 1987. Modern Greek Grammar. London: Croom Helm.

Kay, P. 1997. Words and the Grammar of Context. Stanford, CA: CSLI.

Kripke, S.A. 1972. Naming and necessity. In G. Harman and D. Davidson (eds.), Semantics of Natural Language. Dordrecht: Reidel, 253-355. 
Lambrecht, K. 1994. Information Structure and Sentence Form. Cambridge, MA: Cambridge University Press.

Langacker, R.W. 1991. Foundations of Cognitive Grammar. Volume 2: Descriptive Application. Stanford: Stanford University Press.

Lehrer, A. 1992. Names and naming: Why we need fields and frames. In A. Lehrer and E.F. Kittay (eds.), Frames, Fields, and Contrasts. Hillsdale, N.J.: Lawrence Erlbaum, 123-142.

Leino, P. and J.-O. Östman. 2005. Language change, variability, and functional load. In J. Leino (ed.), Constructional Reorganization. Amsterdam and Philadelphia: John Benjamins, 37-54.

Mackridge, P. 1985. The Modern Greek Language. Oxford: Clarendon Press.

Manolessou, I. and G. Horrocks. 2007. The development of the definite article in Greek. Studies in Greek Linguistics - In memoriam A.-F. Christidis, 224-236.

Marmaridou, S.A.S. 1984. The study of reference, attribution and genericness in the context of English and their grammaticalization in M. Greek noun phrases. Unpublished PhD dissertation, University of Cambridge, UK.

Marmaridou, S.A.S. 1989. Proper names in communication. Journal of Linguistics 25/2: 355-372.

Marmaridou, S.A.S. 1991. What's so Proper about Names? Athens: Parousia Journal Monograph Series 15.

Marmaridou, S. 2011. The relevance of embodiment in lexical and collocational meaning: the case of prosopo in Greek. In Z. Maalej and N. Yu (eds), Embodiment via Outer Body Parts: Studies from Various Languages and Cultures. Amsterdam and Philadelphia: John Benjamins, 256-289.

Marmaridou, S. 2012. The constructional motivation of indefinite generics in Modern Greek. Constructions and Frames 4/2.

Mill, J.S. 1956[1843]. A System of Logic. New York: Longman.

Nikiforidou, K. 2010. Discoursal categories and grammatical description: A constructional integration. Paper presented in plenary at the $6^{\text {th }}$ International Conference on Construction Grammar, Prague, 3-5 September, 2010. 
Nikiforidou, K. 2011. Grammar and Discourse: A Constructional Approach to discourse-based Conventionality. Athens: Parousia Journal Monograph Series, 81.

Pawley, A. 1987. Encoding events in Kalam and English: different logics for reporting experience. In R.S. Tomlin (ed.), Coherence and Grounding in Discourse. Amsterdam and Philadelphia: John Benjamins, 329-360.

Pawley, A. and F.H. Syder. 1983. Two puzzles for linguistic theory: native-like selection and native-like fluency. In J.C. Richards and R.W. Schmidt (eds.), Language and Communication. London and New York: Longman, 191-227.

Peters, A.M. 1983. The Units of Language Acquisition. Cambridge: Cambridge University Press.

Putnam, H. 1975. Mind, Language and Reality. Cambridge: Cambridge University Press.

Russell, B. 1905. On denoting. Mind 14: 479-493.

Searle, J. 1969. Speech Acts. Cambridge: Cambridge University Press.

Sperber, D. and D. Wilson. 1986. Relevance: Communication and Cognition. Oxford: Basil Blackwell.

Strawson, P. F. 1950. On referring. Mind 59: 320-344.

Sweetser, E. and G. Fauconnier 1996. Cognitive links and domains: Basic aspects of mental space theory. In G. Fauconnier and E. Sweetser (eds.), Spaces, Worlds and Grammar. Chicago and London: The University of Chicago Press, 1-28.

Terkourafi, M. 2010. Don't go V-ing in Cypriot Greek: Semantic, pragmatic, and prosodic aspects of a prohibitive construction. Constructions and Frames 2/2: 208-241.

Tomasello, M. 1992. First verbs: A Case Study of Early Grammatical Development. Cambridge, MA: Cambridge University Press.

Tomasello, M. 2000. Do young children have adult syntactic competence? Cognition 74: 209-253.

Traugott, E.C. and R.D. Dasher. 2002. Regularity in Semantic Change. Cambridge: Cambridge University Press. 
Valenzuela Manzanares, J. and A.M. Rojo López. 2008. What can language learners tell us about constructions? In S. De Knop and T. De Rycker (eds.), Cognitive Approaches to Pedagogical Grammar. Berlin and New York: Mouton de Gruyter, 197-230.

Van Langendonck, W. 1999. Neurolinguistic and syntactic evidence for basic level meaning in proper names. Functions of Language 6/1: 95-138.

Vandelanotte, L. and P. Willemse. 2002. Restrictive and non-restrictive modification of proprial lemmas. Word 53/1: 9-36.

Waara, R. 2004. Construal, convention, and constructions in L2 speech. In M. Achard and S. Niemeier (eds.), Cognitive Linguistics, Second Language Acquisition, and Foreign Language Teaching. Berlin and New York: Mouton de Gruyter, 51-75.

Zwicky, A.M. 1974. Hey, whatsyourname!, Papers from the Tenth Regional Meeting of the Chicago Linguistic Society. Chicago: Chicago University Press, 787-801. 
Major Trends in Theoretical and Applied Linguistics 